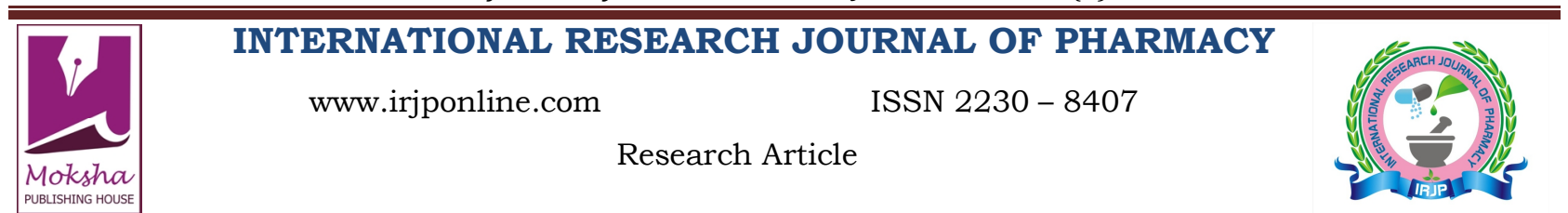

\section{PHYTOCHEMICAL INVESTIGATION ON WITHANIA SOMNIFERA ROOT MARC GENERATED IN AYURVEDIC INDUSTRY}

Rajalakshmy M R ${ }^{1}$, Sindhu A ${ }^{1}$, Geetha $G^{2}$ *

${ }^{1}$ The Arya Vaidya Pharmacy (Coimbatore) Ltd, Palakkad, Kerala, India

${ }^{2} \mathrm{P}$ S G College of Pharmacy, Coimbatore, TN, India

*Corresponding Author Email: ggeetha97@rediffmail.com

Article Received on: 20/07/13 Revised on: 21/07/13 Approved for publication: 11/08/13

DOI: 10.7897/2230-8407.04844

IRJP is an official publication of Moksha Publishing House. Website: www.mokshaph.com

(C) All rights reserved.

\section{ABSTRACT}

Water extraction is a major process in Ayurvedic medicine manufacturing industry. This process involves water extraction of huge quantity of herbs, which culminates in the generation of large amount of marc or herbal residue. Usually the residue is either incinerated or converted to herbal manure. This paper investigates the marc of Withania somnifera roots obtained from Ayurvedic Industry for presence of valuable and potent bioactive phytochemicals. The chances of the phytochemicals getting altered by the process of prolonged heating is also looked into and found that no such genesis or degradation of phytochemicals leading to a new compound has occurred in the marc. As part of study, physicochemical analysis such as total ash percentage, acid insoluble ash percentage and extractive values are performed. Preliminary phytochemical analysis was carried out with different extracts, like hexane, ethyl acetate and methanol of both herb and marc which showed the presence of similar compounds. High Performance Thin Layer Chromatography finger printing and densitogram of hexane, ethyl acetate and methanol extracts of marc and herb showed that there was a reduction in the concentration of the actives in marc. The densitogram of ethyl acetate extract showed absence of certain prominent peaks in marc. In the case of methanol extract the prominent peaks were present in the marc and the concentration of some major actives were reduced in the hexane extract of marc.

Keywords: Withania somnifera, marc, physicochemical phytochemical analysis, HPTLC.

\section{INTRODUCTION}

Withania somnifera (Ws), generally known as Indian Ginseng, is a very potent and widely used herb in Ayurveda and other traditional systems of medicine. It has been used in Indian sub-continent for treatment of several diseases for over 3000 years. Ws is known in English as winter cherry, Aswagandha in Sanskrit, Amukkira in Tamil, and Amukkuram in Malayalam ${ }^{1-2}$. The plant grows wildly in subtropical regions in India such as Madhya Pradesh, Uttar Pradesh, Punjab, and north-western regions of India such as Gujarat and Rajasthan. It belongs to family solenaceae, and the species name somnifera means "sleep-bearing" in Latin, indicating its potent action as a sedative ${ }^{3-4}$. In Ayurveda it is considered as a rasayana herb, for promoting health and longevity by augmenting defense against diseases, arresting aging process, revitalizing the body in debilitated conditions, increasing the capability of the individual to resist environmental factors and creating a sense of wellbeing ${ }^{5}$. Withania somnifera is an ingredient in more than about 40 Ayurvedic formulations. It is also prescribed for a variety of musculoskeletal conditions and as general tonic to increase energy. Biological properties of the plant include antiinflammatory, anti-tumor, anti-cancer, anti-stress, antioxidant, sleep inducing, effective in memory related conditions and insomnia, immunomodulator, hemopoetic, rejuvenating effects, effect on CNS and cardiopulmonary system $^{6-7}$. The officinal parts of Withania somnifera include leaf, root and fruit. Chemical evaluation of this plant is done by different researchers and the presence of active compounds like alkaloids (isopellettierine, anaferine, tropine etc.), steroidal compounds including ergostane type steroidal lactones, withaferin $\mathrm{A}$, withanolide etc has been confirmed. The main active constituents of Withania somnifera root are steroidal alkaloids and steroidal lactones, which belong to class of constituents called withanolides. A phytosteroid, withaferin $\mathrm{A}$, is an active chemical constituent in withanolides $^{8-9}$. Recent research studies ${ }^{10-14}$ show withaferin
A is comparatively more effective in cancer inhibition than doxorubicin, a common chemotherapy drug. The immense therapeutical potential of Withania somnifera roots is attributed by presence of the constituent bioactive compounds, most of which can impart their activity even in very low concentrations. Hundreds of tons of this herb are used annually in Ayurvedic pharmaceutical Industry for manufacturing different formulations. This study is undertaken to explore presence of residual potent bioactive phytochemicals in the marc which is not generally utilized for the value of the material. A comparative study of herb and its marc is also performed.

\section{MATERIALS AND METHODS}

The authenticated Withania somnifera roots were sourced from The AryaVaidya Pharmacy (Coimbatore) Limited. The marc was collected from the industry subsequent to the processing of an Ayurvedic product namely AswagandhadiLehyam. In this process Withania somnifera was extracted thrice, separately with water. The water extraction was taken forward for the further manufacturing processing. The marc so generated was taken for the present study.Analytical grade chemicals were purchased from Nice Chemicals and Merck. The marc sample was dried in sunlight and coarsely powdered. The Withania somnifera herb sample was shade dried and powdered coarsely. Physicochemical investigations such as for Total ash percentage and acid insoluble ash were carried out on both herb and its marc by standard methods ${ }^{15-16}$. The coarse powder of herb and marc were extracted successively by using Soxhlet apparatus. Solvents of increasing polarity such as hexane, ethyl acetate and methanol were used. The extractive percentage was calculated. Preliminary phytochemical analysis was carried out on each extracts separately and compared with that of herb $^{17-25}$. 
Rajalakshmy M R et al. Int. Res. J. Pharm. 2013, 4 (8)

Table 1: Results of Physicochemical Analysis

\begin{tabular}{|c|c|c|}
\hline \multirow{2}{*}{ Tests } & \multicolumn{2}{|c|}{ Observations } \\
\cline { 2 - 3 } & Herb & Marc \\
\hline Hexane Extractive (\%) & 0.603 & 0.368 \\
\hline Ethyl acetate Extractive (\%) & 1.282 & 0.874 \\
\hline Methanol Extractive (\%) & 16.124 & 4.681 \\
\hline Ash (\%) & 6.25 & 2.804 \\
\hline Acid Insoluble Ash (\%) & 0.466 & 0.212 \\
\hline
\end{tabular}

Table 2: Results of Phytochemical Analysis

\begin{tabular}{|c|c|c|c|c|c|c|c|}
\hline Phytochemicals & Test & $\begin{array}{l}\text { Hexane } \\
\text { Extract }\end{array}$ & $\begin{array}{c}\text { Ethyl acetate } \\
\text { extract }\end{array}$ & $\begin{array}{c}\text { Methanol } \\
\text { Extract }\end{array}$ & $\begin{array}{l}\text { Hexane } \\
\text { Extract }\end{array}$ & $\begin{array}{c}\text { Ethyl acetate } \\
\text { extract }\end{array}$ & $\begin{array}{c}\text { Methanol } \\
\text { Extract }\end{array}$ \\
\hline & & \multicolumn{3}{|c|}{ Herb } & \multicolumn{3}{|c|}{ Marc } \\
\hline \multirow[t]{2}{*}{ Carbohydrates } & Molisch's Test & - & + & + & - & + & + \\
\hline & Fehling's Test & - & + & + & - & + & + \\
\hline \multirow[t]{2}{*}{ Phenols } & Phosphomolybdic acid Test & - & + & + & - & + & + \\
\hline & Ferric chloride Test & - & + & + & - & + & + \\
\hline Flavonoids & Schinoda Test & - & + & + & - & + & + \\
\hline Tannins & Braemer's Test & - & - & - & - & - & - \\
\hline Steroids & Liebermann-Burchard's Test & + & - & + & + & - & + \\
\hline Terpenoids & Liebermann-Burchard's Test & - & - & - & - & - & - \\
\hline \multirow[t]{4}{*}{ Alkaloids } & Dragendroff's Test & - & - & + & - & - & + \\
\hline & Mayer's Test & - & - & + & - & - & + \\
\hline & Wagner's Test & - & - & + & - & - & + \\
\hline & Hager's Test & - & - & + & - & - & + \\
\hline Glycosides & Legal's Test & - & + & + & - & + & + \\
\hline $\begin{array}{c}\text { Anthraquinone } \\
\text { Glycosides }\end{array}$ & Borntrager's Test & - & + & + & - & + & + \\
\hline \multirow[t]{2}{*}{ Phytosterols } & Salkowski's Test & + & - & - & + & - & - \\
\hline & Liebermann-Burchard's Test & + & - & - & + & - & - \\
\hline Saponins & Foam Test & - & - & + & - & - & + \\
\hline
\end{tabular}
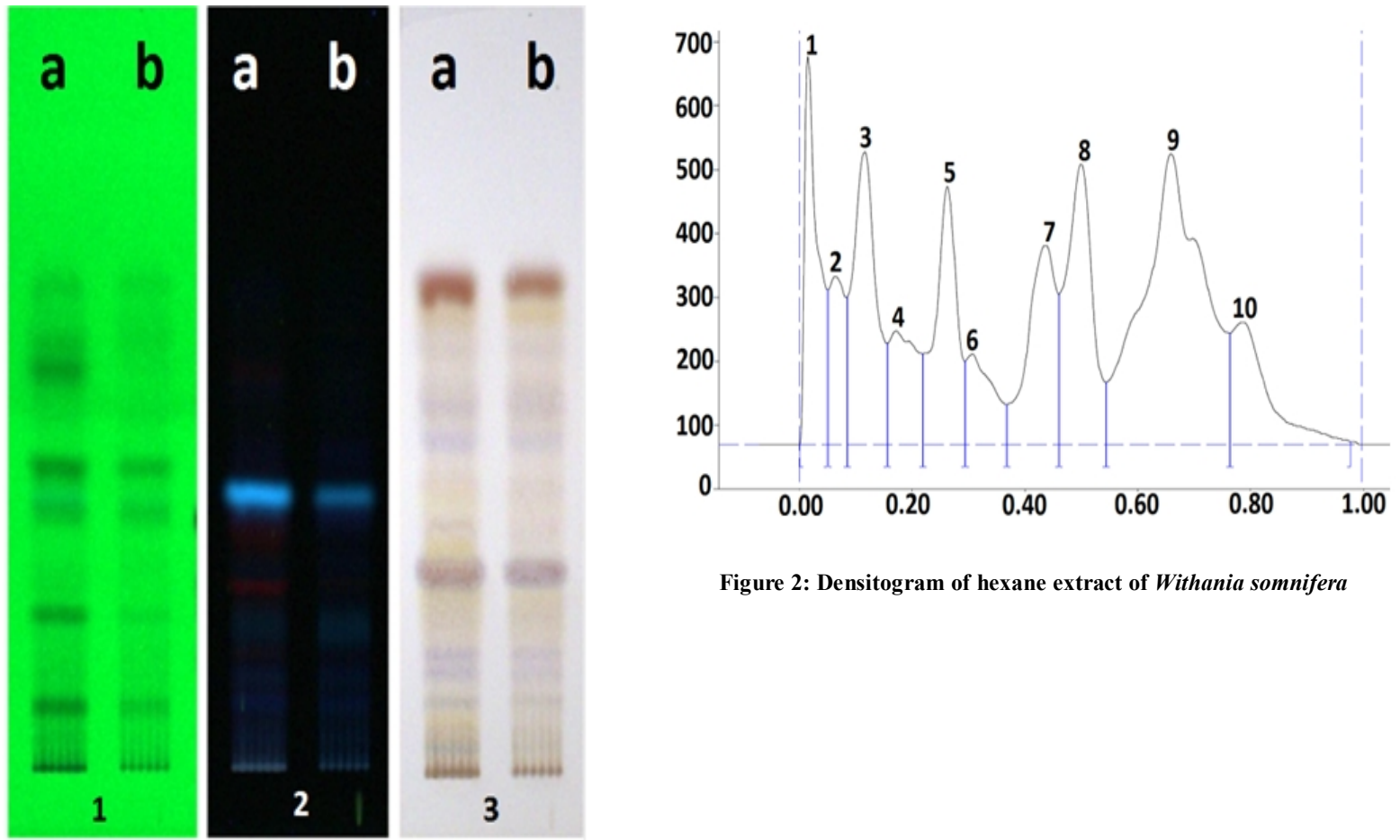

Figure 2: Densitogram of hexane extract of Withania somnifera

Figure 1: HPTLC profiles of hexane extract of (a)

Ws (b) marc at (1) $254 \mathrm{~nm}$, (2) $366 \mathrm{~nm}$, (3)

Derivatised for phenolic compounds 


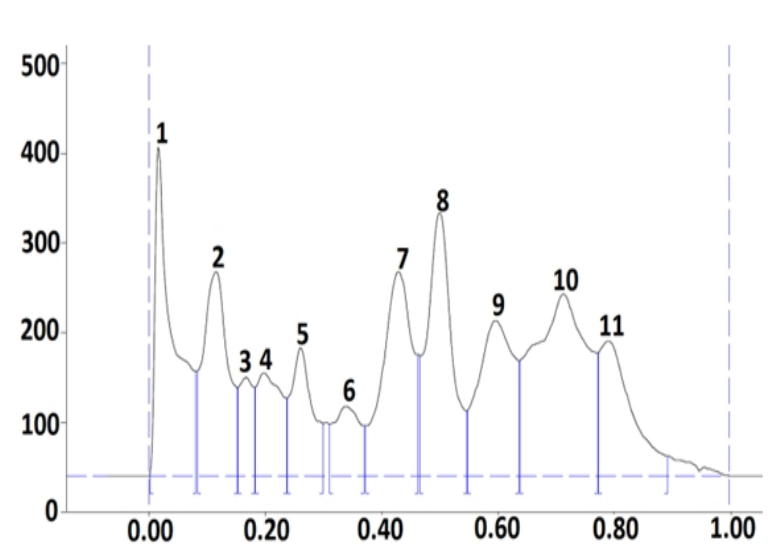

Figure 3: Densitogram of hexane extract of Withania somnifera marc

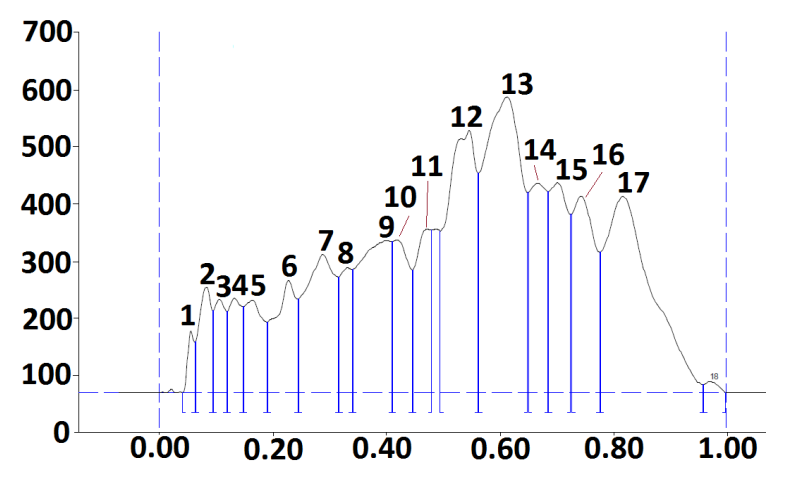

Figure 5: Densitogram of ethyl acetate extract of Withania somnifera
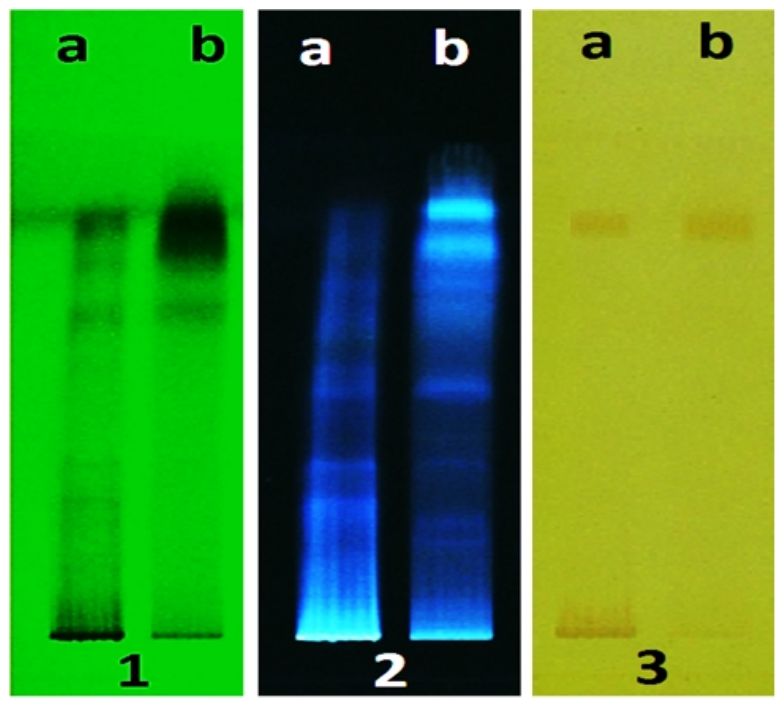

Figure 7: HPTLC profiles of methanol extract of (a) Withania somnifera and (b) marc at (1) $254 \mathrm{~nm}$, (2) $366 \mathrm{~nm}$, (3) Derivatised for alkaloids

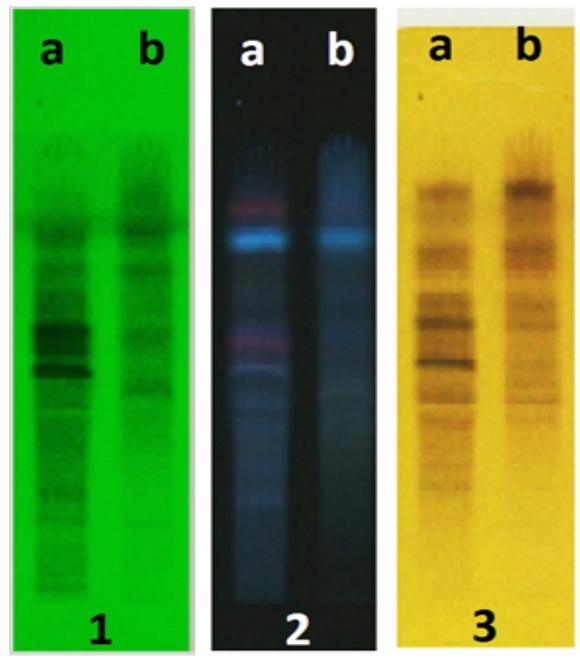

Figure 4: HPTLC profiles of ethyl acetate extract of (a) Ws and (b) marc at (1) $254 \mathrm{~nm}$, (2) $366 \mathrm{~nm}$, (3) Derivatised for phenols

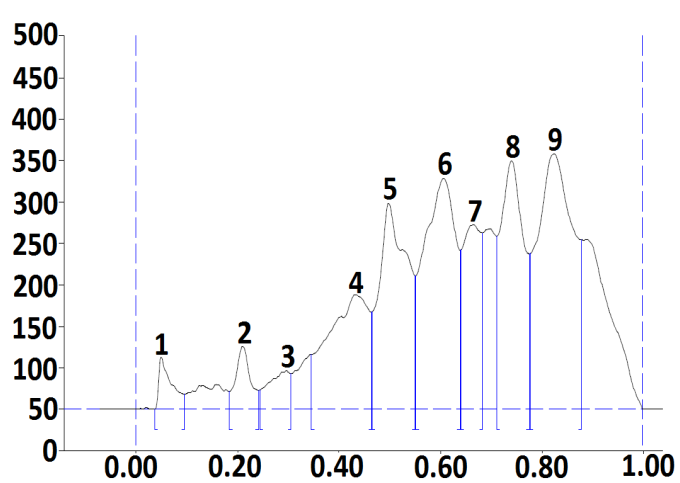

Figure 6: Densitogram of ethyl acetate extract of Withania somnifera marc

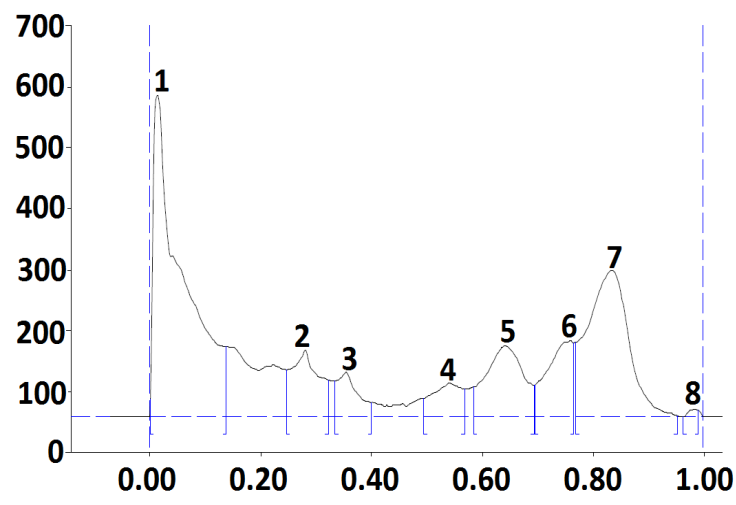

Figure 8: Densitogram of methanol extract of Withania somnifera 


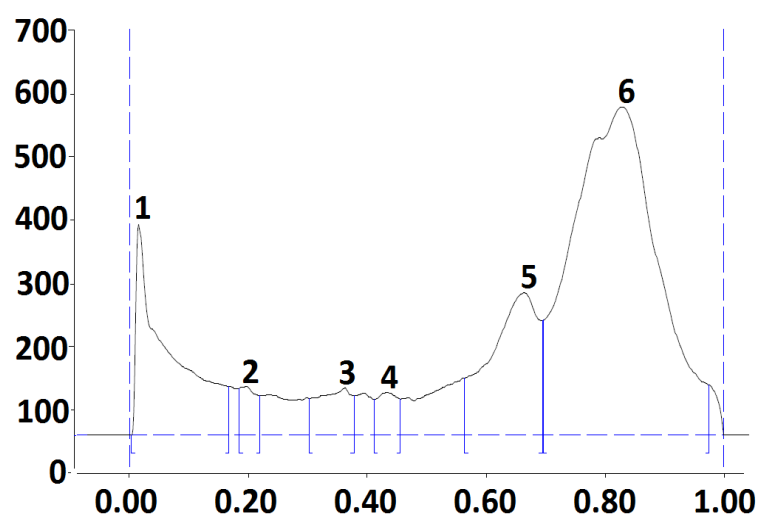

Figure 9: Densitogram of methanol extract of Withania

somnifera marc

HPTLC finger printing was done for phytochemical comparison, using HPTLC Plates, Silica Gel 60 F254. The solvent systems used were Hexane: Ethyl acetate (3:1) for hexane extract, Ethyl acetate: Methanol: Toluene: Water (4:1:1:0.50) for ethyl acetate extract and Chloroform: Methanol (5:5) for methanol extract. Visualization was made at both 254 and $366 \mathrm{~nm}$. The densitogram at $254 \mathrm{~nm}$ was analyzed for presence or absence of any peaks. The plates for Hexane extract were derivatized for phytosterols using Liebermann Burchard reagent. Ferric chloride reagent was used for ethyl acetate extract for visualizing phenolic compounds and in the case of methanol extract, the plate was derivatized for alkaloids using Dragendorff reagent.

\section{RESULTS AND DISCUSSIONS}

The results of physicochemical analysis carried out on Withania somnifera root and its marc is detailed in Table 1. The extracts obtained by successive Soxhlet extraction, were estimated and compared. It was observed that hexane extractive value for marc is about half that for its herb, indicating possibility of leaching the volatile principles into the water extract or escape of the principle while boiling process. The ethyl acetate extract, which contains medium polar phytochemicals, show considerable difference in extractive values between herb and its marc. In the case of methanol extract, the extractive values are very low compared to the herb. An interesting observation is that about $29 \%$ of total extractable matter present in herb is retained in the marc even after taking water decoctions for three times by boiling with water for about twenty four hours. Total ash is generally a measure of inorganic compounds in the substance. It is observed that there is considerable decrease in Total ash percentage for marc which indicates that some inorganic compounds from herb may have gone into water decoction (kashayam). The marc still shows presence of about $2.8 \%$ of inorganic compounds in it. Presence of inorganic compounds such as silica, silicic acid etc., as indicated by acid insoluble ash percentage, is observed to be less in marc than in herb. The results of preliminary phytochemical analysis carried out on different extracts of Withania somnifera and its marc are detailed in Table 2. Hexane extracts of herb and marc reveal presence of steroids and phytosterols in both. The qualitative phytochemical analysis of ethyl acetate extracts and methanol extract for herb and marc are comparable. The HPTLC profiling of the herb and marc, showed the presence of almost similar phytochemicals and the densitogram analysis of various extracts gave a probable concentration of the phytocompounds. The HPTLC profiles of hexane extract of both herb and marc are given in Figure 1. The derivatized plate for phytosterols is also shown in Figure1, Figure 2 and Figure 3 show HPTLC densitogram of hexane extract for Ws and its marc respectively. The major peaks in HPTLC densitogram are observed at peaks $3,5,7,8,10$ in hexane extracts for both herb and marc. However, there is change in peak area indicating lower concentration of compounds in marc compared to herb. The derivatization of plates with Liebermann Burchard reagent confirms presence of phytosterols in marc. HPTLC profile of ethyl acetate extracts of Withania somnifera, its marc and derivatized plate for phenolic compounds, shown in Figure 4, confirm presence of phenols in the two samples. This indicates some retention of phenolic compound in marcs. Densitogram of ethyl acetate extracts of Withania somnifera and its marc are respectively given in Figure 5 and 6 . The major peaks at 12,13 and 17 are present in both samples while minor peaks 2, 3, 4, 5, 8 and 10 are absent in marc. The area under the peaks is lower for marc compared to herb. The methanol extract of both Withania somnifera and its marc are compared by HPTLC method and the profile is detailed in Figure 7. It shows comparable spots at same $R_{f}$ values. The spot at $R_{f}$ of 0.83 is identified as alkaloid by spraying with Dragendorff reagent. Figure 8 and Figure 9 detail corresponding HPTLC densitograms. The compounds corresponding to two prominent peaks 1 and 7 of Withania somnifera are also present in the marc.

\section{CONCLUSION}

The present study explores the qualitative and quantitative analysis of the phytochemicals in a herb and its marc after extraction with water. Marc retain considerable amount of inorganic compounds and secondary plant metabolites. Some compounds are transferred in to the extract resulting in varying decrease in concentrations of that compound in the marc. And there is no indication of any new compound in the marc as a result of processing. The identification of residual compounds and in-vivo activity evaluation of marc are proposed as a continuation of this study, which would provide significant leads to the scope of utilization of marc. 


\section{REFERENCES}

1. Malhotra SC. Phytochemical investigation of certain medicinal plants used in Ayurveda, Central Council for Research in Ayurveda and Siddha, Ministry of Health and Family welfare, Govt. of India, New Delhi; 1990

2. PP Joy, J Thomas, et.al, Medicinal plants, Kerala Agricultural University, Aromatic and Medicinal Research Station; 1998.

3. VV Sivarajan and Indira Balachandran. Ayurvedic drugs and their plant sources, Oxford and IBH Publishing Co. Pvt. Ltd, Bombay; 1994.

4. Bilal Ahmad Mir, Jabeena Khazir, et.al, Botanical, Chemical and Pharmacological review of Withania somnifera (Indian Ginseng): An Ayurvedic Medicinal Plant, Indian Journal of Drug and diseases 2012; 1(6).

5. Sharma Veena, Sharma Sadhana, et.al, Withania somnifera: A Rejuvenating Ayurvedic Medicinal Herb for the Treatment of various Human ailments, International Journal of PharmTech Research 2011; $3(1)$.

6. Qamar Uddhin, L Shamiulla et.al, Phytochemical and Pharmacological profile of Withania somnifera Dunal: A Review, Journal of Applied pharmaceutical Science 2012; 2(1).

7. Singh G, Sharma PK, et.al, Biological activities of Withania somnifera, Annals of Biological Research 2010; 1(3).

8. V Rajpal. Standardisation of Botanicals (Testing and extraction of medicinal herbs), Vol. 1, Eastern Publishers; 2008. p. 12.

9. Mishra Lakshmi C, Singh Betsy B, Simon Dagenais. Scientific Basis for the Therapeutic use of Withania somnifera (Aswagandha): A Review, Alternative Medicine Review 2000; 5(4): 13.

10. The Ayurvedic Pharmacopoeia of India Part 2 (Formulations), 1, Ministry of Welfare (Govt. of India); 2007.

11. Gupta Shefali, Singh SP, et.al, Reversal of oxidative stress by Withania somnifera in Monocrotophos intoxicated broiler, Journal of Veterinary Pharmacology and Toxicology 2008; 7(1).

12. Mehrotra Vidhi, Mehrotra Shubhi, et.al. Antioxidant and antimicrobial activities of aqueous extract of Withania somnifera against methicillinresistant Staphylococcus Aureus, Journal of Microbiology and Biotechnology Research 2011; 1(1).

13. KM Nadkarni. Indian MateriaMedica, Popularprakasan, Bombay, Vol. $1 ; 1976$.

14. Singh Amritpal, Duggal Sanjeev et.al, Withanolides: Phytoconstituents with significant pharmacological activities, International Journal of Green Pharmacy; 2010.
15. DR Lohar. Protocol for Testing- Ayurvedic, Siddha and Unani Medicines, Govt. of India, Department of Ayush, Ministry of Health and Family Welfare, Pharmacopoeial Laboratory for Indian Medicines Ghaziabad; 2007.

16. Harborne JB. Phytochemical Methods: A guide to Modern Techniques of Plant Analysis, $3^{\text {rd }}$ Edition, Springer; 2008.

17. Tiwari Prashant, Kumar Bimledh, et.al, Phytochemical screening and Extraction: A Review, International Pharmaceutica Sciencia 2011; 1(1).

18. Pradhan Pankaj, Joseph Lincy et.al, Pharmacognostic, Phytochemical and Quantitative Investigation of Saraca asoca leaves, Journal of Pharmacy Research 2010; 3(4).

19. Rajalakshmy M R, Sindhu A. Prospects of Commercial Utilization of Water extracted Curcuma longa, Insight Ayurveda-2013, International Research Conference on Ayurvedic Research and Education; 2013.

20. Y Vaghasiya, R Dave, et.al, Phytochemical Analysis of some Medicinal Plants from Western Region of India, Research Journal of Medicinal Plant 2011; 5(5).

21. S Gopalakrishnan, E Vadivel et.al, Phytochemical and Pharmacognostical studies of Tephrosia purpurea Linn. Areal and root parts, Journal of Herbal Medicine and Toxicology 2009; 3(2).

22. Rajalakshmy MR, Sindhu A. Preliminary Phytochemical Screening and Antioxidant activity of an Ayurvedic Formulation: Balarishtam, IJRAP, 2011; 2(6): 1645-1647.

23. Siddiqui Sazada, Verma Arti, et.al, Preliminary Phytochemicals Analysis of some Important Medicinal and Aromatic Plants, Advances in biological research 2009; 3(5-6).

24. Sengupta Rupa. Comparitive In vitro Anthelmintic and Phytochemical Evaluation of Methanolic and Petroleum Ether Extracts of Woodferdia fruiticosa (L) flower, Int. Res. J. Pharm. 2013; 4(7): 159-161. http:// dx.doi.org/10.7897/2230-8407.04735

25. Kadam PV, Yadav KN, et.al, Pharmacognostic, Phytochemical and Physicochemical studies of Piper nigrum Linn. Fruit (Piperaceae), Int. Res. J. Pharm. 2013; 4(5): 189-193. http://dx.doi.org/10.7897/22308407.04538

\section{Cite this article as:}

Rajalakshmy M R, Sindhu A, Geetha G. Phytochemical investigation on Withania somnifera root marc generated in Ayurvedic industry. Int. Res. J. Pharm. 2013; 4(8):223-227 http://dx.doi.org/10.7897/2230-8407.04844 